\title{
Análise crítica da qualidade da dieta da população brasileira segundo o Índice de Alimentação Saudável: uma revisão sistemática
}

\author{
Critical analysis of the diet quality of the Brazilian population \\ according to the Healthy Eating Index: a systematic review
}

Patrícia Regina Silva Moreira ${ }^{1}$

Naruna Pereira Rocha ${ }^{1}$

Luana Cupertino Milagres ${ }^{1}$

Juliana Farias de Novaes ${ }^{1}$

${ }^{1}$ Departamento de Nutrição e Saúde, Universidade Federal de Viçosa. Avenida Peter Henry Rolfs s/n, Campus Universitário. 36570-000 Viçosa MG Brasil.

patrsmoreira@hotmail.com
Abstract In light of the importance of studying instruments that assess the food quality of the population, this study sought to conduct a systematic review of the quality of the diet of the Brazilian population using the Healthy Eating Index (HEI) and duly analyzing its methodology and results. The major electronic databases were used for the selection of studies. After the searches with the key words, 32 articles were included in this review. The growing interest of the scientific community in addressing this issue was observed, with recent studies using this instrument in $\mathrm{Bra}-$ zil. Methodological issues of articles were evaluated and discussed taking into consideration the revised versions and adaptations of the HEI. Some common results were highlighted among the studies such as low consumption of fruit, vegetables and/or dairy products, and the wider consumption of meat and eggs, cholesterol, total fat and saturated fat. Among the articles that address the HEI and socioeconomic aspects it was seen that quality of diet improves both in accordance with the increasing level of education of parents and with the family income in the population studied. The HEI can be used to monitor changes in dietary patterns and also as a nutrition education and health promotion tool.

Key words Healthy Eating Index, Diet, Brazilian population
Resumo Diante da importância de estudar instrumentos que avaliem a qualidade alimentar da população, este trabalho se propõe realizar uma revisão sistemática sobre o Índice de Alimentação Saudável como instrumento utilizado para avaliar a qualidade da dieta da população brasileira, analisando suas metodologias e resultados. Para a seleção de estudos foram utilizadas as principais bases eletrônicas de dados. Após as buscas com os descritores, foram incluidos 32 artigos. Observou-se o crescente interesse da comunidade científica na abordagem deste tema, sendo recentes os estudos que utilizam esse instrumento no Brasil. Foram avaliadas e discutidas as questões metodológicas dos artigos, considerando as versões revisadas, bem como as adaptações do IAS. Foram destacados alguns resultados comuns entre os estudos como o baixo consumo de frutas, vegetais e/ ou leite e derivados e maior consumo dos grupos de carnes e ovos, colesterol, gordura total e gordura saturada. Dentre os artigos que abordaram o IAS e aspectos socioeconômicos, pode-se observar na população estudada que a qualidade da dieta melhora tanto de acordo com o aumento da escolaridade dos pais quanto com a renda da família. O IAS pode ser utilizado para monitorar mudanças no padrão alimentar, bem como ferramenta de educação nutricional e promoção da saúde.

Palavras-chave Índice de Alimentação Saudável, Dieta, População brasileira 


\section{Introdução}

Atualmente, está amplamente difundida a relação entre hábitos alimentares de um indivíduo ou população com seu estado de saúde. Esta relação pode ser avaliada através do tipo de alimento em si ou por grupos alimentares; por seus componentes (nutrientes) ou ainda por padrões alimentares ${ }^{1}$.

No contexto da epidemiologia nutricional, o enfoque permeia a investigação de determinadas patologias e suas possíveis relações com a ingestão de certos nutrientes ${ }^{2}$. A avaliação desta associação pode ser analisada por instrumentos dietéticos que permitam estimar a ingestão alimentar individual e populacional e, assim, identificar seus componentes dentro desse processo de nutrição e saúde 3 .

No tocante da avaliação da qualidade do consumo alimentar, os índices dietéticos estão sendo estudados e aplicados progressivamente. Estes índices possuem medidas combinadas de variáveis individuais (itens ou componentes) e, para cada um deles, expressa uma diferente dimensão do mesmo. Normalmente, os índices possuem escores que são somados no sentido de obter-se um escore final que melhor descreva a condição de saúde, de ambiente e atitudes de uma pessoa ou população4.

Dentre os vários índices existentes, este estudo destaca o Índice de Alimentação Saudável (IAS), originalmente americano (Healthy Eating Index) e desenvolvido por Kennedy et al., em $1995^{5}$, baseando-se nas recomendações do Dietary Guidelines for Americans e no The Food Guide Pyramid. É considerado um instrumento adequado para medir a qualidade global da alimentação na população pela American Dietetic Association (ADA) ${ }^{6}$.

Em 2004, esse instrumento foi adaptado para o Brasil, baseando-se na Pirâmide Alimen$\operatorname{tar}^{7}$ e denominado Índice de Qualidade da Dieta (IQD). Este estudo concluiu que o IQD mostrou-se um instrumento de amplo potencial de uso na epidemiologia nutricional, sendo capaz de descrever e monitorar o padrão alimentar da população e, consequentemente, subsidiar intervenções adequadas ${ }^{8}$.

Um ponto importante a salientar é a nomenclatura dos índices utilizada nos estudos brasileiros. Diante da existência original do Diet Quality Index, traduzido como Îndice de Qualidade da Dieta, e sendo este, composto por diferentes parâmetros de avaliação se comparado ao IAS, equívocos podem ocorrer quando a nomenclatura é a mesma para os dois instrumentos.
O Diet Quality Index - Índice de Qualidade da Dieta, originalmente, foi descrito por Patterson et al. ${ }^{9}$, no qual foi avaliado, através de um recordatório de $24 \mathrm{~h}$ e dois registros alimentares de dias distintos, oito componentes: gordura total, gordura saturada, colesterol, frutas e hortaliças, cereais e leguminosas, proteínas, sódio e cálcio. Para cada componente, pontuação de zero a dois pontos era atribuída de acordo com as recomendações da Diet and Health, dois para consumo acima e zero para consumo abaixo. Categoricamente, a qualidade da dieta permeia numa escala qualitativa de péssima e ótima9 ${ }^{9}$.

Já o Healthy Eating Index - Índice de Alimentação Saudável (IAS), foi desenvolvido por Kennedy et al..$^{5}$ no qual consiste, originalmente, na avaliação de dez componentes alimentares: cereais, hortaliças, frutas, leite, carnes, gordura total, gordura saturada, colesterol, sódio e variedade da dieta. Os inquéritos dietéticos aplicados também foram um recordatório de $24 \mathrm{~h}$ e dois registros alimentares. Para cada componente é atribuída pontuação de zero a dez, sendo categorizado ao final como satisfatório se houver obtenção de escore superior a 80 ; necessidade de melhoria da qualidade, se escores entre 51 e 80; e dieta insatisfatória, se escore inferior a $50^{5}$.

Após definição e esclarecimento dos termos e verificado a ausência de publicações com esta abordagem, este estudo propõe realizar uma revisão sistemática sobre o Índice de Alimentação Saudável como instrumento utilizado para avaliar a qualidade da dieta da população brasileira, analisando suas metodologias e resultados. Foram consideradas suas versões revisadas, bem como suas adaptações para a realidade local, visto a necessidade constante de instrumentos que melhor avaliem a qualidade alimentar dessa população.

\section{Métodos}

Utilizaram-se as bases eletrônicas Medline (National Library of Medicine, Estados Unidos), Lilacs (Literatura Latino-americana e do Caribe em Ciências da Saúde), SciELO (Scientific Eletronic Library Online) e PubMed sem limite de data de publicação. A revisão buscou estudos que avaliaram a qualidade da dieta utilizando como instrumento o Îndice de Alimentação Saudável adaptado do Healthy Eating Index (HEI), um instrumento desenvolvido pelo Departamento de Agricultura dos Estados Unidos para avaliar a qualidade da dieta da população americana. 
zadas como filtros as palavras "Brasil", para

limitar a busca para estudos realizados com a população brasileira, área temática "ciências da saúde e humanas" e "humanos".

As referências bibliográficas dos estudos localizados nas bases de dados foram também rastreadas para localizar outras pesquisas de potencial interesse ao assunto estudado.

Estabelecidos os critérios de inclusão e exclusão, excluíram-se os artigos de revisão de literatura, os que avaliavam populações que não eram brasileiras, dissertações e teses.

A identificação e a seleção dos artigos foram realizadas por três pesquisadores de forma independente, os quais selecionaram inicialmente os estudos pelos títulos e posteriormente pelos resumos obtidos. Após seleção inicial, realizou-se uma nova análise mais criteriosa de todas as publicações, e de forma consensual, foram determinados os estudos a serem incluídos. O período de busca nas bases eletrônicas foi de maio a junho de 2014.

Nesse sentido, realizou-se uma revisão bibliográfica de estudos epidemiológicos realizados com a população brasileira que utilizavam o Índice de Alimentação Saudável, incluindo suas formas adaptadas ou revisadas.

\section{Resultados}

Após as buscas com os descritores, foram encontrados 7573 artigos, sendo selecionados 32 artigos que utilizavam o Índice de Alimentação Saudável para avaliar a dieta da população brasileira (Figura 1) segundo os critérios de exclusão e inclusão. Os artigos selecionados, bem como as principais características dos estudos, são descritos nos Quadros 1 e 2.

Foi possível observar o crescente interesse da comunidade científica brasileira na abordagem deste tema e a utilização deste instrumento como forma de avaliar a qualidade da dieta da população. Os estudos que utilizam esse instrumento no Brasil são recentes, visto que o IAS original foi desenvolvido na década de $90^{5}$, sendo o artigo mais antigo selecionado referente ao ano de 2004.
Dos estudos listados, observou-se uma maior concentração das publicações nas regiões sudeste (63\%), seguida da região sul (22\%), o que chama a atenção para que as outras regiões também tenham o interesse em realizar estudos que abordem a qualidade da dieta, visto que o instrumento pode ser utilizado para monitorar mudanças no padrão alimentar, bem como ferramenta de educação nutricional e promoção da saúde ${ }^{5}$.

Ressalta-se a importância das definições e esclarecimento quanto aos termos IAS e IQD. No entanto, para fins de avaliação das metodologias, optou-se por manter a nomenclatura dada pelos autores no artigo original. Foi observada a utilização do termo IQD em $25 \%$ dos estudos selecionados $(\mathrm{n}=8)$ quando estes, na prática, aplicaram o IAS.

Um dos parâmetros que diferencia as questões metodológicas dos artigos é o critério de pontuação, no qual a maior parte (72\%) utiliza a pontuação de 0 a 100 pontos, que foi o primeiro critério, bem como a primeira classificação proposta por Bowman et al. ${ }^{6}$. Os demais utilizaram uma pontuação de 0 a 120 que foi proposta posteriormente por Mota et al. ${ }^{10}$.

Foi observado que $41 \%$ dos estudos $(n=13)$ citou baixo consumo de frutas, vegetais e/ou leite e derivados ${ }^{11-23}$. Já em relação aos componentes com o maior consumo, destacaram-se os grupos de carnes e ovos, colesterol, gordura total e gordura saturada ${ }^{11,15,17,24-28}$. Alguns estudos ${ }^{17,20}$ relataram que a elevada ingestão de carne vermelha e processada esteve associado a uma pior qualidade da dieta.

Santos et al. ${ }^{17}$ também destacaram a necessidade de melhorar a ingestão do grupo de leite e derivados, ressaltando que o consumo deve ser de produtos lácteos magros, pois ao ingerir quantidade elevada desse grupo alimentar podese aumentar o consumo total de gordura saturada e colesterol. Alguns estudos destacaram que o grupo das frutas apresentou o maior percentual de pontuação zero devido a baixa ingestão deste grupo pela população brasileira ${ }^{8,16,19,29}$.

Todos os artigos desta revisão utilizaram como instrumento base a versão do IAS de $1995^{5}$, exceto o estudo de Loreiro et al. ${ }^{11}$, que utilizou uma referência mais atualizada ${ }^{30}$. Nenhuma pesquisa utilizou a referência de Guenther et al. ${ }^{31}$, sendo esta a mais recente atualização do IAS.

Dentre os artigos que abordaram o índice de alimentação saudável e aspectos socioeconômicos pode-se observar, na população estudada, que a qualidade da dieta melhora tanto de acordo com o aumento da escolaridade dos 


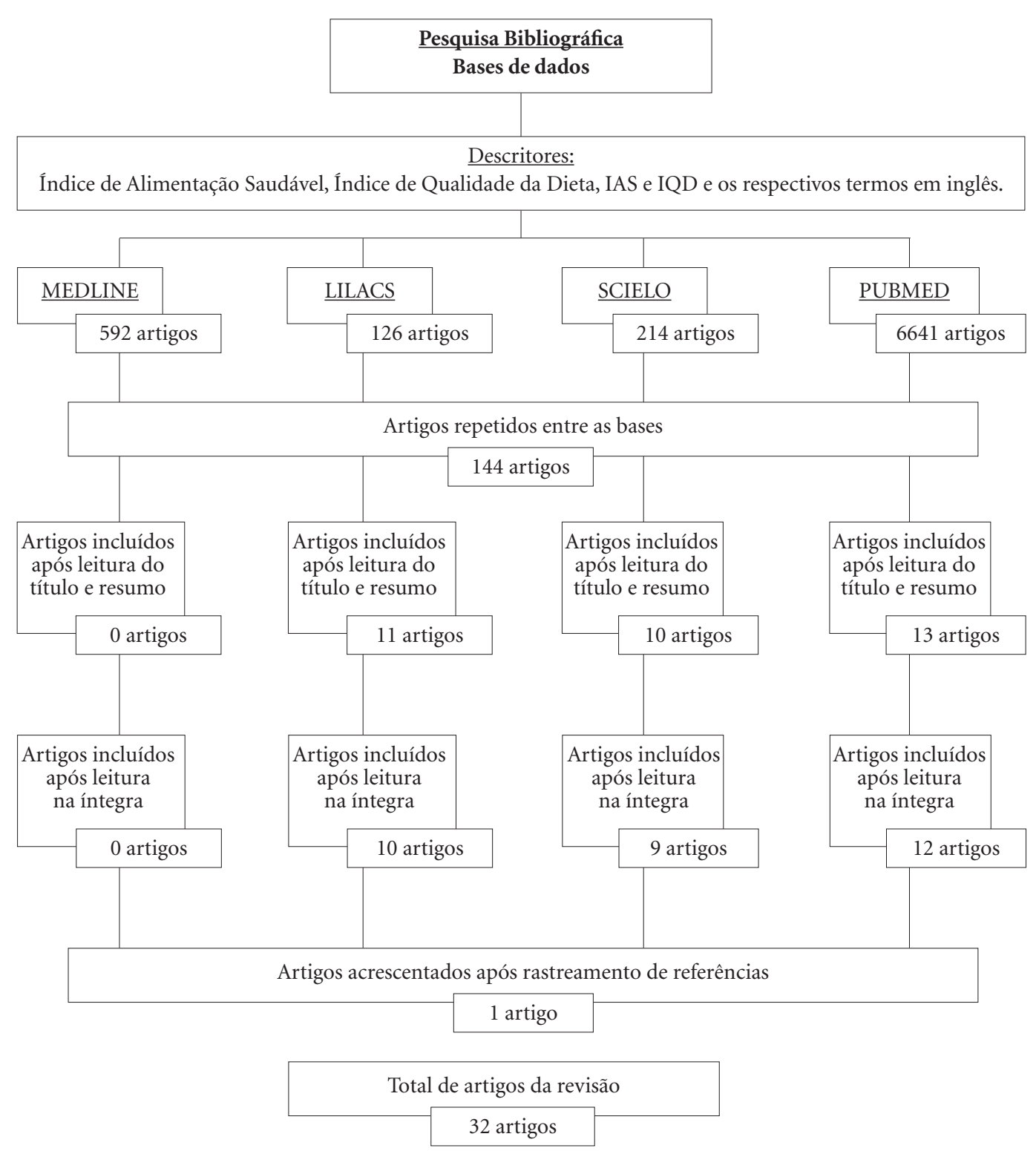

Figura 1. Número de artigos selecionados após critérios de inclusão e exclusão com os descritores em inglês e português.

pais e/ou quanto melhor for a renda da família $^{12,17-19,21,28,29,32,33}$.

A Figura 2 apresenta o histórico e tendências do IAS desde sua criação em 1995.

\section{Discussão}

Esta revisão demonstrou importantes pontos que caracterizaram a qualidade da dieta da população brasileira, apontando os grupos alimentares que merecem atenção para tornar a dieta saudável. Os grupos mais discutidos pelos estudos foram os de frutas, verduras e legumes, leite e derivados e os referentes à gordura. 
Quadro 1. Avaliação metodológica dos artigos selecionados sobre IAS com a população brasileira.

\begin{tabular}{|c|c|c|c|c|c|c|}
\hline No & Autor/Ano & Delineamento & Amostra & $\begin{array}{c}\text { Local do } \\
\text { Estudo }\end{array}$ & Objetivo & Instrumento \\
\hline 1 & $\begin{array}{l}\text { Fisberg et } \\
\text { al., } 2004^{8}\end{array}$ & Transversal & $\begin{array}{l}50 \text { indivíduos } \\
\text { de ambos os } \\
\text { sexos. }\end{array}$ & $\begin{array}{l}\text { Botucatu, } \\
\text { SP. }\end{array}$ & $\begin{array}{l}\text { Adaptar e aplicar o HEI } \\
\text { norte-americano para } \\
\text { avaliar a qualidade da dieta } \\
\text { de indivíduos brasileiros. }\end{array}$ & $\begin{array}{l}\text { IQD }{ }^{* *} \text { adaptado } \\
\text { por Fisberg et } \\
\text { al., } 2004^{8} .\end{array}$ \\
\hline 2 & $\begin{array}{l}\text { Godoy et } \\
\text { al., } 2006^{12}\end{array}$ & Transversal & $\begin{array}{l}437 \\
\text { adolescentes } \\
\text { entre } 12 \mathrm{e} \\
19 \text { anos de } \\
\text { ambos os } \\
\text { sexos. }\end{array}$ & Butantã, SP. & $\begin{array}{l}\text { Avaliar a qualidade da } \\
\text { dieta dos adolescentes } \\
\text { segundo o sexo e a } \\
\text { escolaridade dos chefes da } \\
\text { família. }\end{array}$ & $\begin{array}{l}\text { IQD adaptado } \\
\text { por Fisberg } \\
\text { et al., } 2004^{8} \text {, } \\
\text { modificado por } \\
\text { Godoy et al., } \\
2006^{12} \text {. }\end{array}$ \\
\hline 3 & $\begin{array}{l}\text { Barbosa et } \\
\text { al., } 2006^{34}\end{array}$ & Transversal & $\begin{array}{l}437 \\
\text { adolescentes } \\
\text { entre } 12 \mathrm{e} \\
19 \text { anos de } \\
\text { ambos os } \\
\text { sexos. }\end{array}$ & Butantã, SP. & $\begin{array}{l}\text { Avaliar a qualidade da } \\
\text { dieta dos adolescentes } \\
\text { segundo o sexo e a } \\
\text { escolaridade dos chefes da } \\
\text { família. }\end{array}$ & $\begin{array}{l}\text { HEI } \\
\text { estabelecido } \\
\text { por Kennedy et } \\
\text { al. }^{5}, 1995 .\end{array}$ \\
\hline 4 & $\begin{array}{l}\text { Gomes e } \\
\text { Cyrillo, } \\
2006^{32}\end{array}$ & Transversal & $\begin{array}{l}284 \text { mulheres } \\
\text { entre } 20 \text { e } 50 \\
\text { anos. }\end{array}$ & $\begin{array}{l}\text { São Paulo, } \\
\text { SP. }\end{array}$ & $\begin{array}{l}\text { Analisar a relação entre a } \\
\text { utilização de rótulos dos } \\
\text { alimentos embalados e a } \\
\text { qualidade da alimentação. }\end{array}$ & $\begin{array}{l}\text { IAS adaptado } \\
\text { por Bowman et } \\
\text { al. }{ }^{6}, 1998 .\end{array}$ \\
\hline 5 & $\begin{array}{l}\text { Domenes } \\
\text { et al., } \\
2006^{27}\end{array}$ & Transversal & $\begin{array}{l}94 \text { pré- } \\
\text { escolares entre } \\
2 \text { e } 6 \text { anos. }\end{array}$ & $\begin{array}{l}\text { Campinas, } \\
\text { SP. }\end{array}$ & $\begin{array}{l}\text { Avaliar a aplicação } \\
\text { do HEI para uso no } \\
\text { Brasil, empregando- } \\
\text { se como referência } \\
\text { para porcionamento e } \\
\text { classificação dos alimentos } \\
\text { consumidos em grupos as } \\
\text { DAPBs. }\end{array}$ & $\begin{array}{l}\text { IAS } \\
\text { adaptado ao } \\
\text { porcionamento } \\
\text { e classificação } \\
\text { dos alimentos } \\
\text { de acordo com } \\
\text { as DAPBs. }\end{array}$ \\
\hline 6 & $\begin{array}{l}\text { Fisberg et } \\
\text { al., } 2006^{29}\end{array}$ & Transversal & $\begin{array}{l}3.454 \text { adultos } \\
\text { de ambos os } \\
\text { sexos. }\end{array}$ & $\begin{array}{l}\text { Regiões do } \\
\text { Estado de } \\
\text { São Paulo. }\end{array}$ & $\begin{array}{l}\text { Analisar a qualidade da } \\
\text { dieta associada a outros } \\
\text { fatores entre os adultos } \\
\text { que vivem em regiões do } \\
\text { Estado de São Paulo. }\end{array}$ & $\begin{array}{l}\text { IQD adaptado } \\
\text { por Fisberg et } \\
\text { al. } 2004^{8} .\end{array}$ \\
\hline 7 & $\begin{array}{l}\text { Morimoto } \\
\text { et al., } \\
2008^{19}\end{array}$ & Transversal & $\begin{array}{l}1.840 \text { adultos } \\
\text { de ambos os } \\
\text { sexos. }\end{array}$ & $\begin{array}{l}\text { Regiões do } \\
\text { Estado de } \\
\text { São Paulo. }\end{array}$ & $\begin{array}{l}\text { Avaliar os fatores } \\
\text { demográficos, } \\
\text { socioeconômicos e de } \\
\text { estilo de vida associados } \\
\text { à qualidade da dieta de } \\
\text { adultos. }\end{array}$ & $\begin{array}{l}\text { IQD adaptado } \\
\text { por Fisberg et } \\
\text { al., } 2004^{8} \text {. }\end{array}$ \\
\hline 8 & $\begin{array}{l}\text { Gomes et } \\
\text { al., } 2008^{18}\end{array}$ & Transversal & $\begin{array}{l}295 \text { mulheres } \\
\text { com idade } \\
\text { entre } 20 \text { e } 50 \\
\text { anos. }\end{array}$ & $\begin{array}{l}\text { São Paulo, } \\
\text { SP. }\end{array}$ & $\begin{array}{l}\text { Descrever o consumo } \\
\text { alimentar de mulheres } \\
\text { adultas, utilizando o } \\
\text { IAS como medida- } \\
\text { resumo da qualidade da } \\
\text { alimentação, bem como os } \\
\text { componentes desse índice. }\end{array}$ & $\begin{array}{l}\text { IAS adaptado } \\
\text { por Bowman et } \\
\text { al., } 1998^{6} \text {. }\end{array}$ \\
\hline
\end{tabular}


Quadro 1. continuação

\begin{tabular}{|c|c|c|c|c|c|c|}
\hline No & Autor/Ano & Delineamento & Amostra & $\begin{array}{l}\text { Local do } \\
\text { Estudo }\end{array}$ & Objetivo & Instrumento \\
\hline 9 & $\begin{array}{l}\text { Mota et al., } \\
2008^{10}\end{array}$ & Transversal & $\begin{array}{l}502 \\
\text { indivíduos } \\
\text { de ambos os } \\
\text { sexos. }\end{array}$ & $\begin{array}{l}\text { Botucatu, } \\
\text { SP. }\end{array}$ & $\begin{array}{l}\text { Adaptar o IAS norte- } \\
\text { americano ao Guia } \\
\text { Alimentar para a } \\
\text { População Brasileira e } \\
\text { à Pirâmide Alimentar } \\
\text { Adaptada. }\end{array}$ & $\begin{array}{l}\text { IAS adaptado } \\
\text { a Pirâmide } \\
\text { Alimentar } \\
\text { Adaptada } \\
\text { brasileira e ao } \\
\text { Guia Alimentar } \\
\text { da população } \\
\text { brasileira por } \\
\text { Mota et al. } \\
2008^{10} \text {. }\end{array}$ \\
\hline 10 & $\begin{array}{l}\text { Santos et } \\
\text { al., } 2009^{17}\end{array}$ & Transversal & $\begin{array}{l}67 \text { diabéticos } \\
\text { tipo II de } \\
\text { ambos os } \\
\text { sexos. }\end{array}$ & $\begin{array}{l}\text { Rio de } \\
\text { Janeiro, RJ. }\end{array}$ & $\begin{array}{l}\text { Avaliar a qualidade } \\
\text { nutricional do consumo } \\
\text { alimentar de diabéticos } \\
\text { tipo II através do IAS. }\end{array}$ & $\begin{array}{l}\text { HEI } \\
\text { estabelecido } \\
\text { por Kennedy et } \\
\text { al., } 1995^{5} \text {. }\end{array}$ \\
\hline 11 & $\begin{array}{l}\text { Nespeca } \\
\text { e Cyrillo, } \\
2010^{16}\end{array}$ & Transversal & $\begin{array}{l}276 \\
\text { funcionários } \\
\text { públicos de } \\
\text { ambos os } \\
\text { sexos. }\end{array}$ & $\begin{array}{l}\text { São Paulo, } \\
\text { SP. }\end{array}$ & $\begin{array}{l}\text { Avaliar a qualidade da } \\
\text { dieta dos funcionários não } \\
\text { docentes da Universidade } \\
\text { de São Paulo por meio do } \\
\text { IAS. }\end{array}$ & $\begin{array}{l}\text { IAS adaptado } \\
\text { por Fisberg et } \\
\text { al., } 2004^{8} .\end{array}$ \\
\hline 12 & $\begin{array}{l}\text { Vitolo et } \\
\text { al., } 2010^{35}\end{array}$ & Intervenção & $\begin{array}{l}500 \text { pares } \\
\text { mãe-filho de } \\
\text { baixa renda. }\end{array}$ & $\begin{array}{l}\text { São } \\
\text { Leopoldo, } \\
\text { RS. }\end{array}$ & $\begin{array}{l}\text { Avaliar o impacto do } \\
\text { programa da política } \\
\text { nacional sobre a qualidade } \\
\text { da dieta de pré-escolares, } \\
\text { utilizando-se o IAS. }\end{array}$ & \begin{tabular}{|l} 
HEI \\
estabelecido \\
por Kennedy et \\
al. $1995^{5}$ com \\
adaptações \\
realizadas pelos \\
autores para \\
esse estudo.
\end{tabular} \\
\hline 13 & $\begin{array}{l}\text { Jaime et al., } \\
2010^{36}\end{array}$ & Transversal & 737 adultos. & $\begin{array}{l}\text { São Paulo, } \\
\text { SP. }\end{array}$ & $\begin{array}{l}\text { Desenvolver um } \\
\text { índice de qualidade da } \\
\text { dieta ajustado para as } \\
\text { necessidades de energia } \\
\text { (IQD-a) e aplicar o índice } \\
\text { a uma amostra de adultos } \\
\text { brasileiros. }\end{array}$ & $\begin{array}{l}\text { IQD ajustado } \\
\text { por energia } \\
\text { desenvolvido } \\
\text { pelos autores. }\end{array}$ \\
\hline 14 & $\begin{array}{l}\text { Tardivo et } \\
\text { al., } 2010^{25}\end{array}$ & Transversal & $\begin{array}{l}173 \text { mulheres } \\
\text { no com idade } \\
\text { entre } 45 \text { e } 75 \\
\text { anos. }\end{array}$ & $\begin{array}{l}\text { Sudeste do } \\
\text { Brasil. }\end{array}$ & $\begin{array}{l}\text { Investigar a associação } \\
\text { entre a qualidade da } \\
\text { dieta, usando o IAS, e } \\
\text { os indicadores de risco } \\
\text { metabólicos em mulheres } \\
\text { pós-menopáusicas. }\end{array}$ & $\begin{array}{l}\text { HEI } \\
\text { estabelecido } \\
\text { por Kennedy et } \\
\text { al., } 1995^{5} \text {. }\end{array}$ \\
\hline 15 & $\begin{array}{l}\text { Portero- } \\
\text { McLellan et } \\
\text { al., } 2010^{28}\end{array}$ & Transversal & $\begin{array}{l}448 \text { adultos } \\
\text { com idade } \\
\text { entre } 35 \text { e } 85 \\
\text { anos. }\end{array}$ & $\begin{array}{l}\text { Não relata } \\
\text { o local do } \\
\text { estudo. }\end{array}$ & $\begin{array}{l}\text { Identificar a influência das } \\
\text { gorduras dietéticas sobre } \\
\text { o IMC e a circunferência } \\
\text { abdominal em uma } \\
\text { amostra populacional de } \\
\text { adultos. }\end{array}$ & $\begin{array}{l}\text { IAS adaptado } \\
\text { por Mota et al. } \\
2008^{10} .\end{array}$ \\
\hline
\end{tabular}




\begin{tabular}{|c|c|c|c|c|c|c|}
\hline \multicolumn{7}{|c|}{ Quadro 1. continuação } \\
\hline No & Autor/Ano & Delineamento & Amostra & $\begin{array}{l}\text { Local do } \\
\text { Estudo }\end{array}$ & Objetivo & Instrumento \\
\hline 16 & $\begin{array}{l}\text { Silva et al., } \\
2011^{15}\end{array}$ & Transversal & $\begin{array}{l}246 \\
\text { indivíduos } \\
\text { de ambos os } \\
\text { sexos }\end{array}$ & $\begin{array}{l}\text { Inhaumas, } \\
\text { BA. }\end{array}$ & $\begin{array}{l}\text { Descrever a frequência de } \\
\text { SM e comparar o padrão } \\
\text { de consumo alimentar } \\
\text { através do HEI (1995) e de } \\
\text { exames bioquímicos entre } \\
\text { adultos, com ou sem SM, } \\
\text { vivendo em área rural do } \\
\text { Brasil. }\end{array}$ & $\begin{array}{l}\text { HEI } \\
\text { estabelecido } \\
\text { por Kennedy et } \\
\text { al., } 1995^{5} \text {. }\end{array}$ \\
\hline 17 & $\begin{array}{l}\text { Felippe et } \\
\text { al., } 2011^{37}\end{array}$ & Caso Controle & $\begin{array}{l}100 \\
\text { indivíduos } \\
\text { adultos ( } 54 \\
\text { casos e } 46 \\
\text { controles) } \\
\text { de ambos os } \\
\text { sexos }\end{array}$ & $\begin{array}{l}\text { Porto } \\
\text { Alegre, RS. }\end{array}$ & $\begin{array}{l}\text { Comparar a qualidade } \\
\text { da dieta de indivíduos } \\
\text { expostos e não expostos } \\
\text { a um programa de } \\
\text { reeducação alimentar, } \\
\text { utilizando o IAS. }\end{array}$ & $\begin{array}{l}\text { IAS adaptado } \\
\text { por Mota et al. } \\
2008^{10} \text {. }\end{array}$ \\
\hline 18 & $\begin{array}{l}\text { Pimentel et } \\
\text { al., } 2011^{26}\end{array}$ & Transversal & $\begin{array}{l}624 \text { adultos } \\
\text { de ambos os } \\
\text { sexos }\end{array}$ & $\begin{array}{l}\text { Botucatu, } \\
\text { SP. }\end{array}$ & $\begin{array}{l}\text { Verificar a associação da } \\
\text { ingestão de diferentes } \\
\text { gorduras dietéticas com } \\
\text { a qualidade da dieta, } \\
\text { homocisteinemia e } \\
\text { resistência insulínica em } \\
\text { adultos. }\end{array}$ & $\begin{array}{l}\text { IAS adaptado } \\
\text { por Mota et al. } \\
2008^{10} \text {. }\end{array}$ \\
\hline 19 & $\begin{array}{l}\text { Da Costa et } \\
\text { al., } 2012^{13}\end{array}$ & Transversal & $\begin{array}{l}169 \text { mulheres } \\
\text { praticantes } \\
\text { de atividade } \\
\text { física. }\end{array}$ & Aracaju, SE. & $\begin{array}{l}\text { Avaliar a qualidade } \\
\text { da dieta de mulheres } \\
\text { praticantes de atividade } \\
\text { física, através do IQD. }\end{array}$ & $\begin{array}{l}\text { IQD } \\
\text { modificado por } \\
\text { Godoy et al., } \\
2006^{12} \text {. }\end{array}$ \\
\hline 20 & $\begin{array}{l}\text { De Oliveira } \\
\text { et al., } \\
2012^{38}\end{array}$ & Transversal & $\begin{array}{l}335 \\
\text { indivíduos } \\
\text { com idade } \\
\text { entre } 44-65 \\
\text { anos de } \\
\text { ambos os } \\
\text { sexos. }\end{array}$ & $\begin{array}{l}\text { Botucatu, } \\
\text { SP. }\end{array}$ & $\begin{array}{l}\text { Associar a HAS com } \\
\text { fatores dietéticos } \\
\text { (utilizando o IAS) de } \\
\text { adultos clinicamente } \\
\text { selecionados para } \\
\text { programa de mudança de } \\
\text { estilo de vida. }\end{array}$ & $\begin{array}{l}\text { IAS adaptado } \\
\text { por Mota et al. } \\
2008^{10} \text {. }\end{array}$ \\
\hline 21 & $\begin{array}{l}\text { Carvalho et } \\
\text { al., } 2012^{20}\end{array}$ & Transversal & $\begin{array}{l}1677 \\
\text { indivíduos } \\
\text { com idade } \\
\text { superior a } 19 \\
\text { anos. Sendo } \\
847 \text { adultos e } \\
830 \text { idosos. }\end{array}$ & $\begin{array}{l}\text { Estado de } \\
\text { São Paulo }\end{array}$ & $\begin{array}{l}\text { Avaliar o consumo } \\
\text { de carne vermelha e } \\
\text { processada, e o impacto } \\
\text { que consumo tem sobre } \\
\text { a qualidade da dieta e o } \\
\text { ambiente. }\end{array}$ & $\begin{array}{l}\text { IAS-revisado } \\
\text { (IAS-R) de } \\
\text { Previdelli et al., } \\
2011^{39} .\end{array}$ \\
\hline 22 & $\begin{array}{l}\text { Louzada et } \\
\text { al., } 2012^{40}\end{array}$ & Transversal & $\begin{array}{l}228 \text { idosos } \\
\text { entre } 60 \text { e } \\
90 \text { anos de } \\
\text { ambos os } \\
\text { sexos. }\end{array}$ & $\begin{array}{l}\text { Carlos } \\
\text { Barbosa, RS. }\end{array}$ & $\begin{array}{l}\text { Avaliar os fatores } \\
\text { associados à qualidade da } \\
\text { dieta de idosos de uma } \\
\text { cidade no sul do Brasil. }\end{array}$ & $\begin{array}{l}\text { HEI } \\
\text { estabelecido } \\
\text { por Kennedy et } \\
\text { al., } 1995^{5} \text {. }\end{array}$ \\
\hline
\end{tabular}


Quadro 1. continuação

\begin{tabular}{|c|c|c|c|c|c|c|}
\hline No & Autor/Ano & Delineamento & Amostra & $\begin{array}{c}\text { Local do } \\
\text { Estudo }\end{array}$ & Objetivo & Instrumento \\
\hline 23 & $\begin{array}{l}\text { Rauber et } \\
\text { al., } 2013^{21}\end{array}$ & Transversal & $\begin{array}{l}345 \text { crianças } \\
\text { de } 3 \text { a } 4 \text { anos } \\
\text { de idade. }\end{array}$ & $\begin{array}{l}\text { São } \\
\text { Leopoldo, } \\
\text { RS. }\end{array}$ & $\begin{array}{l}\text { Avaliar a qualidade } \\
\text { geral da dieta de pré- } \\
\text { escolares de baixo } \\
\text { status socioeconômico } \\
\text { e identificar fatores } \\
\text { maternos e familiares } \\
\text { associados a essa } \\
\text { pontuação e seus } \\
\text { componentes. }\end{array}$ & $\begin{array}{l}\text { HEI } \\
\text { estabelecido } \\
\text { por Kennedy et } \\
\text { al., } 1995^{5} \text {. }\end{array}$ \\
\hline 24 & $\begin{array}{l}\text { Melendez- } \\
\text { Araújo et } \\
\text { al., } 2012^{41}\end{array}$ & Intervenção & 32 pacientes. & Brasília, DF. & $\begin{array}{l}\text { Avaliar o impacto de } \\
\text { diferentes intervenções } \\
\text { nutricionais sobre o peso } \\
\text { corporal, o consumo de } \\
\text { energia e qualidade da } \\
\text { dieta em pacientes obesos } \\
\text { mórbidos durante o } \\
\text { período pré-operatório. }\end{array}$ & $\begin{array}{l}\text { IAS adaptado } \\
\text { por Mota et al., } \\
2008^{10} \text {. }\end{array}$ \\
\hline 25 & $\begin{array}{l}\text { Assumpção } \\
\text { et al., } \\
2012^{33}\end{array}$ & Transversal & $\begin{array}{l}409 \\
\text { adolescentes } \\
\text { de } 12 \text { a } 19 \\
\text { anos de } \\
\text { ambos os } \\
\text { sexos. }\end{array}$ & $\begin{array}{l}\text { Campinas, } \\
\text { SP. }\end{array}$ & $\begin{array}{l}\text { Avaliar a qua-lidade global } \\
\text { da dieta e a adequação } \\
\text { do consumo de cada } \\
\text { componente da dieta de } \\
\text { adolescentes segundo } \\
\text { fatores demográficos, } \\
\text { socioeconômicos e IMC. }\end{array}$ & $\begin{array}{l}\text { IAS modificado } \\
\text { por Godoy et } \\
\text { al., } 2006^{12} \text {. }\end{array}$ \\
\hline 26 & $\begin{array}{l}\text { Melere et } \\
\text { al., } 2013^{42}\end{array}$ & Transversal & $\begin{array}{l}712 \text { gestantes } \\
\text { entre a } 16^{\mathrm{a}} \mathrm{e} \\
36^{\mathrm{a}} \text { semana de } \\
\text { gestação, com } \\
\text { idade de } 12 \text { a } \\
49 \text { anos. }\end{array}$ & $\begin{array}{l}\text { Porto Alegre } \\
\text { e Bento } \\
\text { Gonçalves, } \\
\text { RS. }\end{array}$ & $\begin{array}{l}\text { Avaliar a qualidade global } \\
\text { da dieta em uma amostra } \\
\text { de gestantes brasileiras a } \\
\text { partir de um parâmetro } \\
\text { único, simples e objetivo. }\end{array}$ & $\begin{array}{l}\text { HEIP-B } \\
\text { adaptado à } \\
\text { população } \\
\text { gestante pelos } \\
\text { autores do } \\
\text { estudo. }\end{array}$ \\
\hline 27 & $\begin{array}{l}\text { Malta et al., } \\
2013^{14}\end{array}$ & Transversal & $\begin{array}{l}73 \text { indivíduos } \\
\text { de ambos os } \\
\text { sexos com } \\
\text { idade } \geq 60 \\
\text { anos. }\end{array}$ & Avaré, SP. & $\begin{array}{l}\text { Avaliar a qualidade da } \\
\text { dieta da população idosa } \\
\text { do município de Avaré-SP } \\
\text { através do IAS. }\end{array}$ & $\begin{array}{l}\text { IAS adaptado } \\
\text { por Mota et al. } \\
2008^{10} \text {. }\end{array}$ \\
\hline 28 & $\begin{array}{l}\text { Loureiro et } \\
\text { al., } 2013^{11}\end{array}$ & Transversal & $\begin{array}{l}195 \text { adultos de } \\
20 \text { a } 50 \text { anos } \\
\text { de ambos os } \\
\text { sexos. }\end{array}$ & Cuiabá, MT. & $\begin{array}{l}\text { Analisar a qualidade da } \\
\text { dieta e identificar fatores } \\
\text { associados em adultos, } \\
\text { através do IQD-R. }\end{array}$ & $\begin{array}{l}\text { IQD-R } \\
\text { adaptado por } \\
\text { Previdelli et al., } \\
2011^{39} .\end{array}$ \\
\hline 29 & $\begin{array}{l}\text { De Lima et } \\
\text { al., } 2013^{23}\end{array}$ & Transversal & $\begin{array}{l}747 \\
\text { beneficiários } \\
\text { do PBF, a } \\
\text { partir dos } 19 \\
\text { anos de idade. } \\
\text { de ambos os } \\
\text { sexos. }\end{array}$ & $\begin{array}{l}\text { Curitiba, } \\
\text { PR. }\end{array}$ & $\begin{array}{l}\text { Avaliar a qualidade da } \\
\text { dieta dos beneficiários do } \\
\text { programa Bolsa Família. }\end{array}$ & $\begin{array}{l}\text { IAS adaptado } \\
\text { por Fisberg et } \\
\text { al., } 2004^{8} .\end{array}$ \\
\hline
\end{tabular}

continua 


\begin{tabular}{|c|c|c|c|c|c|c|}
\hline \multicolumn{7}{|c|}{ Quadro 1. continuação } \\
\hline No & Autor/Ano & Delineamento & Amostra & $\begin{array}{c}\text { Local do } \\
\text { Estudo }\end{array}$ & Objetivo & Instrumento \\
\hline 30 & $\begin{array}{l}\text { Tavares et } \\
\text { al., } 2013^{43}\end{array}$ & Transversal & $\begin{array}{l}75 \text { nutrizes } \\
\text { em } \\
\text { aleitamento } \\
\text { exclusivo a } \\
\text { partir do } 28^{\circ} \\
\text { dia pós-parto. }\end{array}$ & $\begin{array}{l}\text { São Paulo, } \\
\text { SP. }\end{array}$ & $\begin{array}{l}\text { Identificar estado } \\
\text { nutricional, consumo } \\
\text { alimentar e qualidade } \\
\text { da dieta de nutrizes em } \\
\text { amamentação exclusiva. }\end{array}$ & $\begin{array}{l}\text { IAS adaptado } \\
\text { por Mota et al. } \\
2008^{10} \text {. }\end{array}$ \\
\hline 31 & $\begin{array}{l}\text { Wendpap } \\
\text { et al., } \\
2014^{24}\end{array}$ & Transversal & $\begin{array}{l}1.326 \\
\text { adolescentes } \\
\text { de escolas } \\
\text { públicas e } \\
\text { privadas de } \\
\text { ambos os } \\
\text { sexos. }\end{array}$ & Cuiabá, MT. & $\begin{array}{l}\text { Analisar a qualidade da } \\
\text { dieta pelo IQD-Revisado e } \\
\text { fatores associados. }\end{array}$ & $\begin{array}{l}\text { IQD-Revisado } \\
\text { adaptado por } \\
\text { Mota et al. } \\
2008^{10} \text {. }\end{array}$ \\
\hline 32 & $\begin{array}{l}\text { Rauber et } \\
\text { al., } 2014^{22}\end{array}$ & Longitudinal & $\begin{array}{l}500 \text { pares } \\
\text { mãe-filho. } \\
\text { Crianças: } \\
3 \text { a } 4 \text { anos }= \\
356 \text { avaliadas } \\
7 \text { a } 8 \text { anos }= \\
315 \text { avaliadas }\end{array}$ & $\begin{array}{l}\text { São } \\
\text { Leopoldo, } \\
\text { RS. }\end{array}$ & $\begin{array}{l}\text { Determinar mudanças } \\
\text { na qualidade da dieta } \\
\text { de crianças, usando } \\
\text { dados longitudinais de } \\
\text { uma amostra de pré } \\
\text { - escolar (3-4 anos) e } \\
\text { escolar (7-8 anos), as } \\
\text { quais as mães receberam } \\
\text { aconselhamento dietético } \\
\text { durante o primeiro ano } \\
\text { de vida em práticas de } \\
\text { alimentação infantil. }\end{array}$ & $\begin{array}{l}\text { HEI } \\
\text { estabelecido } \\
\text { por Kennedy et } \\
\text { al., } 1995^{5} \text {. }\end{array}$ \\
\hline
\end{tabular}

Siglas: HEI: Health Eating Index, DAPBs: Diretrizes Alimentares para a População Brasileira, IQD: Índice de Qualidade da Dieta, IMC: Índice de Massa Corporal, SM: Síndrome Metabólica, HAS: Hipertensão Arterial Sistemica, IQD-R: Índice de Qualidade da Dieta Revisado, PBF: Programa Bolsa Família, HEIP-B: Índice de Alimentação Saudável para Gestantes Brasileiras.

Nota: *Pontuação segundo proposto por Mota et al. ${ }^{10}$, considera pontuação máxima de 120 pontos; ${ }^{* *}$ IQD: Índice de Qualidade da dieta adaptado por Fisberg et al. ${ }^{8}$ para população Brasileira segundo o HEI (1995).

A avaliação do consumo alimentar da população é importante apesar das limitações encontradas $^{44}$, pois permite analisar e identificar suas características, especialmente as práticas não saudáveis, e abordá-las em programas de educação nutricional, proporcionando melhores condições de saúde à população, além de avaliar a qualidade total da dieta e não apenas componentes isolados ${ }^{5}$.

De acordo com a pesquisa de Vigilância de Fatores de Risco e Proteção para Doenças Crônicas por Inquérito Telefônico (Vigitel), realizada no Brasil em 2013 $3^{45}$ o consumo alimentar da população foi avaliado em relação ao consumo de frutas e hortaliças. Os pesquisadores encontraram que os adultos que consumiam regularmente frutas e hortaliças variaram entre $23,4 \%$ a $46,0 \%$. Percebe-se que o consumo desse grupo alimentar é baixo na população brasileira e, essas modificações do padrão alimentar já são observadas em publicações que confirmam um consumo insuficiente de carboidratos complexos e fibras, aumento do consumo de gorduras e açúcares refinados ${ }^{46,47}$, que concordam com os resultados dos estudos agrupados nesta revisão. 
Quadro 2. Pontuação total e resultados obtidos com a utilização do IAS na população brasileira.

\begin{tabular}{|c|c|c|}
\hline No & Pontuação Obtida & Resultados principais \\
\hline 1 & $\begin{array}{l}\text { Média do IAS }=51,5 \text { pontos } \\
\text { (necessidade de melhora). } \\
74 \% \text { da população com dieta } \\
\text { necessitando de melhorias e } \\
14 \% \text { com dieta inadequada. }\end{array}$ & $\begin{array}{l}\text { Observado consumo elevado dos componentes de gordura total, } \\
\text { gordura saturada, colesterol e sódio. Os maiores percentuais de } \\
\text { observações com valor zero foram atribuídos ao item frutas e gordura } \\
\text { saturada. }\end{array}$ \\
\hline 2 & $\begin{array}{l}\text { Média do IAS = } 58,4 \text { pontos } \\
\text { (necessidade de melhora). } \\
68 \% \text { da população classificada } \\
\text { com dieta necessitando de } \\
\text { melhorias e } 28 \% \text { com dieta } \\
\text { inadequada. }\end{array}$ & $\begin{array}{l}\text { Os adolescentes do sexo masculino apresentaram maior pontuação nos } \\
\text { componentes: cereais, pães e raízes, hortaliças, leguminosas e variedade } \\
\text { da dieta, enquanto que para sódio ocorreu o inverso. A escolaridade do } \\
\text { chefe da família, os componentes cereais, pães e raízes, hortaliças, leite } \\
\text { e derivados, e variedade de alimentos tiveram correlação positiva. }\end{array}$ \\
\hline 3 & $\begin{array}{l}\text { Média do IAS }=74,5 \text { pontos } \\
\text { (necessidade de melhoria); após } \\
6 \text { meses, média do IAS }=93,8 \\
\text { pontos (dieta adequada). }\end{array}$ & $\begin{array}{l}\text { Houve diferença significativa }(\mathrm{p}<0,05) \text { entre as médias das porções } \\
\text { de frutas e vegetais, com base na pirâmide alimentar Americana e um } \\
\text { escore satisfatório do IAS após } 6 \text { meses de frequência da criança na } \\
\text { creche. }\end{array}$ \\
\hline 4 & $\begin{array}{l}\text { A média dos escores do IAS foi } \\
\text { de } 63,6 \text { (alimentação pouco } \\
\text { saudável). }\end{array}$ & $\begin{array}{l}\text { Uma associação positiva foi encontrada entre as mulheres que tinham } \\
\text { o hábito de ler os rótulos dos alimentos e maior IAS }(\mathrm{p}<0,05) \text {, porém } \\
\text { com pontuação no status de alimentação pouco saudável. }\end{array}$ \\
\hline 5 & $\begin{array}{l}\text { O valor para o IAS para as } \\
\text { meninas foi de } 73,97 \text { e para os } \\
\text { meninos } 75,70 .\end{array}$ & $\begin{array}{l}\text { Independente do gênero } 70 \% \text { dos pré-escolares apresentaram IAS entre } \\
\text { o intervalo de } 80 \text { a } 51 \text { pontos, necessitando de intervenção nutricional. } \\
\text { A aplicação mostrou baixo consumo de cereais, verduras e legumes e } \\
\text { excesso no consumo de leguminosas, carnes, ovos, laticínios, gordura } \\
\text { saturada e açúcares. }\end{array}$ \\
\hline 6 & $\begin{array}{l}\text { Média do IQD: } 60,4 \text { pontos. } \\
\text { Com } 73,4 \% \text { classificados com } \\
\text { dieta que exigia modificações e } \\
21,6 \% \text { com dieta inadequada. }\end{array}$ & $\begin{array}{l}\text { A qualidade da dieta esteve positivamente relacionada à escolaridade } \\
\text { do chefe da família, número de bens de consumo duráveis, idade e } \\
\text { consumo de energia e, inversamente associada ao IMC e tabagismo. } \\
\text { O consumo de vegetais, frutas e leite melhorou com o aumento da } \\
\text { escolaridade, embora geralmente com baixa pontuação. }\end{array}$ \\
\hline 7 & $\begin{array}{l}\text { Média do IQD: } 60,42 \text { pontos; } \\
\text { Com } 75 \% \text { da população } \\
\text { classificada com dieta } \\
\text { necessitando de modificações e } \\
21 \% \text { com dieta inadequada. }\end{array}$ & $\begin{array}{l}\text { Observaram-se médias baixas para os componentes: frutas, verduras } \\
\text { e legumes, leite e derivados. Número de bens de consumo duráveis, } \\
\text { escolaridade do chefe da família e ter } 60 \text { anos ou mais se associaram } \\
\text { positivamente ao IQD em homens. Para as mulheres, ter } 60 \text { anos ou } \\
\text { mais se associou ao IQD. }\end{array}$ \\
\hline 8 & $\begin{array}{l}\text { A média dos escores do IAS foi } \\
\text { de } 63,6 \text { pontos (alimentação } \\
\text { pouco saudável). }\end{array}$ & $\begin{array}{l}\text { A qualidade da dieta não apresentou diferenças entre os estratos } \\
\text { sociais. A variação foi encontrada no consumo segundo alguns dos } \\
\text { componentes do IAS. }\end{array}$ \\
\hline 9 & $\begin{array}{l}\text { Dos indivíduos avaliados } 71 \% \\
\text { estavam com dieta necessitando } \\
\text { de melhorias (Média IAS=87,2) } \\
\text { e } 14 \% \text { com dietas de má } \\
\text { qualidade (Média IAS }=62,2 \text { ). }\end{array}$ & $\begin{array}{l}\text { O IAS adaptado pode ser utilizado na população brasileira para avaliar } \\
\text { os hábitos alimentares populacionais. A pontuação do instrumento } \\
\text { variou de } 0 \text { a } 120 \text { pontos. A maioria da população teve sua dieta } \\
\text { avaliada como necessitando de melhorias. }\end{array}$ \\
\hline 10 & $\begin{array}{l}7,5 \% \text { foi considerada com } \\
\text { uma alimentação pobre (IAS = } \\
45,0 \pm 1,6 \text { e CV: } 0,32 \text { ) e } 52,2 \% \\
\text { necessitavam melhorar a dieta } \\
(\mathrm{IAS}=67,8 \pm 7,0 \text { e CV: } 0,10)\end{array}$ & $\begin{array}{l}\text { A população avaliada necessita modificar os hábitos alimentares, } \\
\text { especialmente quanto ao consumo à ingestão de produtos lácteos } \\
\text { magros, frutas e vegetais. }\end{array}$ \\
\hline
\end{tabular}


Quadro 2. continuação

\begin{tabular}{|c|c|c|}
\hline No & Pontuação Obtida & Resultados principais \\
\hline 11 & $\begin{array}{l}\text { A média do valor do IAS } \\
\text { encontrada foi de } 68,08 \\
( \pm 10,75) \text { equivalendo à } \\
\text { dieta com necessidades de } \\
\text { modificação. }\end{array}$ & $\begin{array}{l}\text { A maioria da população avaliada necessita melhorar o consumo } \\
\text { alimentar em termos qualitativos. Ao se separar a amostra em } \\
\text { grupos conforme IMC, escolaridade e renda, não foram encontradas } \\
\text { diferenças estatísticas nos valores do instrumento utilizado. }\end{array}$ \\
\hline
\end{tabular}

12 A média do IAS foi de $66,8 \pm$ 11,2 para todas as crianças. $79,7 \%$ foram classificadas

Houve grande efeito do programa de intervenção durante o primeiro ano da vida, porque ele também foi eficaz na promoção de uma dieta como precisando melhorar a qualidade da dieta consumida.

13 Média do IQD-a: Mulheres: 59,2 pontos e Homens: 56,7 pontos.

melhor qualidade em toda a infância.

14 Média do IAS: 60 pontos; $48,5 \%$ da população com dieta precisando de melhorias e $8,5 \%$ com dieta inadequada.

O IQD-a proposto pode ser usado em inquéritos epidemiológicos/ estudos de avaliação do comportamento alimentar em uma população semelhante ao do estudo. Recomenda-se que, o índice de pontuação deva ser baseado nas necessidades estimadas de energia.

Não foram encontradas correlações significativas do IAS com indicadores de risco metabólico. O percentual de gordura corporal foi maior entre as mulheres com necessidade de melhoria da dieta ou com dieta pobre. A dieta das mulheres com necessidade de melhorias foi atribuída à ingestão elevada de gordura saturada.

15 A média do IAS para o grupo

O IAS foi maior no grupo de maior renda devido ao maior consumo de maior renda foi de 82,93 e o de proteína $(+12,8 \%)$, laticínios $(\mathrm{p}<0,001)$, hortaliças $(\mathrm{p}<0,01)$, frutas grupo de menor renda, 77,98 com $\mathrm{p}=0,004$ para os dois grupos.

16 A média da pontuação da qualidade da dieta obtida para os grupos com SM e sem SM foi de 56,9 (Intervalo: 12-99).

17 Grupo caso: IAS = 97 pontos; grupo controle $=84,2$ pontos; $\mathrm{p}<0,001$.

$(\mathrm{p}<0,001)$ e menor de gordura $(-9,8 \%)$.

Ambos os grupos tiveram baixa pontuação para o consumo de vegetais, frutas, leites e derivados. O grupo com SM obteve em geral pontuações mais baixas que o grupo controle.

A pontuação do IAS foi maior no grupo de exposição do que no grupo controle, concluindo que a exposição à reeducação alimentar apresenta dieta com melhor qualidade.

18 Valor médio do IAS-ad $=80$

O consumo de lipídios saturados ( $>8 \%$ do VET) e/ou colesterol pontos (pontuação do método de 0 a 120 pontos).

(>165 mg/d), porções de óleo vegetal (>1,5-2,0/dia) e/ou gordura poliinsaturada, representam os principais fatores lipídicosdietéticos associados a má qualidade da dieta, resistência insulínica e hiperhomocisteinemia de adultos.

19 Média do IQD = 66,6 pontos (necessidade de melhoria). $90,6 \%$ da população apresentou dieta com necessidade de modificações.

20 Média do IAS semelhante em ambos os grupos: com HAS $=$ 82,5 pontos e sem $\mathrm{HAS}=82,1$ pontos (dieta adequada).

Mulheres obesas apresentaram menor consumo de hortaliças que as não obesas. Os componentes colesterol e sódio obtiveram maiores percentuais para escore 10 .

Observou-se correlação positiva da pressão arterial diastólica com o consumo de colesterol e açúcar. A variedade da dieta $\geq 8$ itens alimentares, apresentou efeito protetor para alterações da pressão arterial sistólica (OR $=0,361$ IC 0,148-0,878). 
Quadro 2. continuação

\begin{tabular}{|c|c|c|}
\hline No & Pontuação Obtida & Resultados principais \\
\hline 21 & $\begin{array}{l}\text { Média do IAS com consumo } \\
\text { moderado: Homens: } 59,6 ; \\
\text { Mulheres: } 57,9 \text {. } \\
\text { Com consumo elevado: } \\
\text { Homens: } 54,5 \text { e Mulheres: } 56,2 \text {. }\end{array}$ & $\begin{array}{l}\text { O excesso de consumo de carne vermelha e processada esteve } \\
\text { associado a uma pior qualidade da dieta em homens. A dieta esteve } \\
\text { negativamente relacionada a leite e derivados e positivamente } \\
\text { relacionada com os vegetais em mulheres. Aconselham reduzir } \\
\text { a ingestão de carne vermelha e processada para quantidades } \\
\text { recomendadas, como parte de uma dieta saudável. }\end{array}$ \\
\hline 22 & $\begin{array}{l}\text { Média do IAS: } 66,63 ; 9,7 \% \text {. } \\
80,9 \% \text { da população com dieta } \\
\text { precisando de melhorias e } 9,4 \% \\
\text { com dieta inadequada. }\end{array}$ & $\begin{array}{l}\text { Apenas o estado civil mostrou um efeito independente sobre o IAS. } \\
\text { Indivíduos casados apresentaram maior chance de ter uma dieta } \\
\text { adequada. Os resultados sugerem que a qualidade da dieta deste grupo } \\
\text { necessita de melhorias. }\end{array}$ \\
\hline 23 & $\begin{array}{l}\text { Média do IAS: } 65,7 \text { pontos } \\
79,7 \% \text { da amostra com dieta } \\
\text { necessitando de melhorias e } \\
10,7 \% \text { com dieta inadequada. }\end{array}$ & $\begin{array}{l}\text { Neste grupo de pré-escolares as características maternas e familiares } \\
\text { não foram associadas com total de pontos do IAS. Foram afetados o } \\
\text { consumo de leite e a variedade da dieta, que foi maior entre aqueles } \\
\text { cujas mães tinham níveis mais elevados de escolaridade. O consumo } \\
\text { de gordura total e saturada foi menor entre aqueles cujas mães tinham } \\
\text { níveis mais elevados de escolaridade. }\end{array}$ \\
\hline 24 & $\begin{array}{l}\text { Média do IAS: Grupo } \\
\text { Intervenção Padrão: } 80 \text { pontos; } \\
\text { Grupo Intervenção intensiva: } 77 \\
\text { pontos. } 73 \% \text { da população com } \\
\text { dieta precisando de melhorias e } \\
25,4 \% \text { com dieta inadequada. }\end{array}$ & $\begin{array}{l}\text { Ambas as intervenções nutricionais promoveram perda de peso, } \\
\text { redução do consumo de energia e melhoria da qualidade alimentar em } \\
\text { obesos mórbidos durante o período pré-operatório. A pontuação do } \\
\text { instrumento utilizado variava de } 0 \text { a } 120 \text { pontos. }\end{array}$ \\
\hline 25 & $\begin{array}{l}\text { Média do IQD: } 59,7 \text { pontos; } \\
\text { Meninos }-60,5 \text { pontos e } \\
\text { meninas }-58,9 \text { pontos. }\end{array}$ & $\begin{array}{l}\text { O IQD global esteve associado so } \neg \text { mente com o sexo; porém, a } \\
\text { escolaridade do chefe da família e a renda mostraram que quanto } \\
\text { maiores podem ter melhores pontuações nos componentes. Ressaltam } \\
\text { que é relevante analisar separadamente cada componente do indicador. }\end{array}$ \\
\hline 26 & $\begin{array}{l}\text { De acordo com o HEIP-B, a } \\
\text { média encontrada foi de } 67,4 \text {. } \\
62,6 \% \text { apresentaram } \\
\text { pontuações equivalentes a dieta } \\
\text { com necessidade de melhorias. }\end{array}$ & $\begin{array}{l}\text { A qualidade da dieta da maioria das gestantes foi classificada como } \\
\text { precisando de melhorias além de ter apresentado boas correlações com } \\
\text { os nutrientes em investigação no período gestacional. }\end{array}$ \\
\hline 27 & $\begin{array}{l}\text { Os resultados evidenciaram } \\
\text { que } 32,9 \% \text { dos idosos avaliados } \\
\text { apresentaram dieta de má } \\
\text { qualidade e } 60,3 \% \text { com dieta } \\
\text { classificada como necessitando } \\
\text { de melhorias. }\end{array}$ & $\begin{array}{l}\text { A maioria dos idosos estudados apresentavam uma dieta que } \\
\text { necessitava de melhorias, com baixo consumo de frutas, hortaliças, } \\
\text { carboidratos preferencialmente complexos e leite e derivados em } \\
\text { relação as porções recomendadas pela pirâmide brasileira. }\end{array}$ \\
\hline 28 & $\begin{array}{l}\text { Mulheres: melhor pontuação } \\
\text { para frutas inteiras e sódio } \\
(\mathrm{p}<0,01) \text {. } \\
\text { Homens: maiores escores para } \\
\text { óleos, oleaginosas e gordura de } \\
\text { peixe }(p=0,02) \text {. }\end{array}$ & $\begin{array}{l}\text { Indivíduos com idade igual ou superior a } 30 \text { anos obtiveram maior } \\
\text { pontuação para o IQD-R total, fruta inteira, gordura saturada e } \\
\text { calorias provenientes de gordura sólida, álcool e açúcar de adição. }\end{array}$ \\
\hline
\end{tabular}




\begin{tabular}{|c|c|c|}
\hline \multicolumn{3}{|c|}{ Quadro 2. continuação } \\
\hline No & Pontuação Obtida & Resultados principais \\
\hline 29 & $\begin{array}{l}\text { Média do IQD = } 51 \text { pontos } \\
\text { (necessidade de melhora). }\end{array}$ & $\begin{array}{l}\text { A média geral do IQD identificou necessidade de melhora da dieta } \\
\text { da população. A população possui uma dieta monótona, com um } \\
\text { consumo adequado de leguminosas, porém baixo para frutas, verduras } \\
\text { e produtos lácteos. }\end{array}$ \\
\hline 30 & $\begin{array}{l}\text { Média do IAS = 72,3 pontos } \\
\text { (necessidade de melhora). }\end{array}$ & $\begin{array}{l}\text { As nutrizes apresentaram sobrepeso, consumo energético abaixo do } \\
\text { recomendado, porcentagens de macronutrientes adequadas exceto para } \\
\text { proteína, que foi elevada. A dieta foi classificada como precisando de } \\
\text { melhorias, conforme o Îndice de Alimentação Saudável. }\end{array}$ \\
\hline 31 & $\begin{array}{l}\text { Média do IQD-R = 75,1 pontos } \\
\text { (necessidade de melhora). }\end{array}$ & $\begin{array}{l}\text { Foi observado que tempo } \geq 300 \text { minutos por semana de atividade } \\
\text { física e excesso de peso dos adolescentes foram associados a maiores } \\
\text { pontuações do IQD-R. Estilo de vida saudável foi associado à dieta de } \\
\text { melhor qualidade. }\end{array}$ \\
\hline 32 & $\begin{array}{l}\text { Grupo de intervenção: } 86,2 \% \\
\text { das crianças de } 3-4 \text { anos de } \\
\text { idade e } 94,7 \% \text { das crianças de } \\
7-8 \text { anos de idade, classificadas } \\
\text { com dietas pobres ou que } \\
\text { necessitavam de melhoria. A } \\
\text { média do HEI - } 3 \text { a } 4 \text { anos: } 68,2 \\
\text { e } 7 \text { a } 8 \text { anos: } 65,1 .\end{array}$ & $\begin{array}{l}\text { As mudanças na qualidade da dieta ao longo do tempo ilustram a } \\
\text { perda do efeito de intervenção aos 7-8 anos de idade. } \\
\text { Em ambos os grupo (controle e intervenção), a pontuação para o } \\
\text { consumo de frutas e leite diminuiu ao longo do tempo, enquanto que } \\
\text { a pontuação para a ingestão de gordura saturada e variedade alimentar } \\
\text { aumentou. }\end{array}$ \\
\hline
\end{tabular}

Siglas: IAS: Índice de Alimentação Saudável, SM: Síndrome Metabólica, IQD: Índice de Qualidade da Dieta, IQD-R: Índice de Qualidade da Dieta Revisado, HEI: Health Eating Index, HEIP-B: Índice de Alimentação Saudável para Gestantes Brasileiras, IASad: Índice de Alimentação Saudável adaptado. IQD-a: Índice de Qualidade da Dieta ajustado por necessidade de energia.

Vale ressaltar que o critério utilizado no Vigitel foi ter consumido pelo menos um alimento do grupo ao dia e não levou em consideração a adequação em relação a porções diárias recomendadas pelos guias alimentares brasileiros, portanto, possivelmente esta frequência pode estar superestimada para adequação de consumo.

Segundo a Pesquisa de Orçamento Familiar (2008-2009), a prevalência de ingestão de gordura saturada acima do limite recomendado foi de $82 \%$ na população ${ }^{48}$. Alguns dos estudos avaliados apontam para um elevado consumo de gordura, incluindo a saturada, como o principal componente para caracterizar uma dieta como de má qualidade.

Todas as publicações selecionadas obtiveram pontuações classificadas como necessitando de melhorias (variaram entre 51 e 87,2), apesar das diferenças dos pontos de corte entre os trabalhos avaliados e das diferentes metodologias dos instrumentos.
As pesquisas que utilizam índices para avaliar a qualidade da dieta costumam ter pontos de corte diferentes que refletem as adaptações realizadas no instrumento ${ }^{42}$. A classificação inicial da qualidade da dieta encontrada nos artigos foi proposta por Bowman et al. ${ }^{6}$, que definiu categorias para o HEI (1995), a fim de caracterizar a qualidade da dieta da população avaliada, considerando uma dieta inadequada aquela com pontuação inferior a 51 pontos, dieta em que são necessárias modificações entre 51 e 80 pontos, e uma dieta saudável aquela com pontuação superior a 80 pontos.

Outro tipo de pontuação foi proposto por Mota et al. ${ }^{10}$, ao adaptar o IAS ao Guia e a pirâmide alimentar para a população brasileira, dessa forma, a alteração ocorreu em função do acréscimo de três novos componentes (grupos das leguminosas, açúcares e gorduras) e à exclusão do componente sódio. Com 12 componentes, o método poderia ter uma pontuação máxima de 


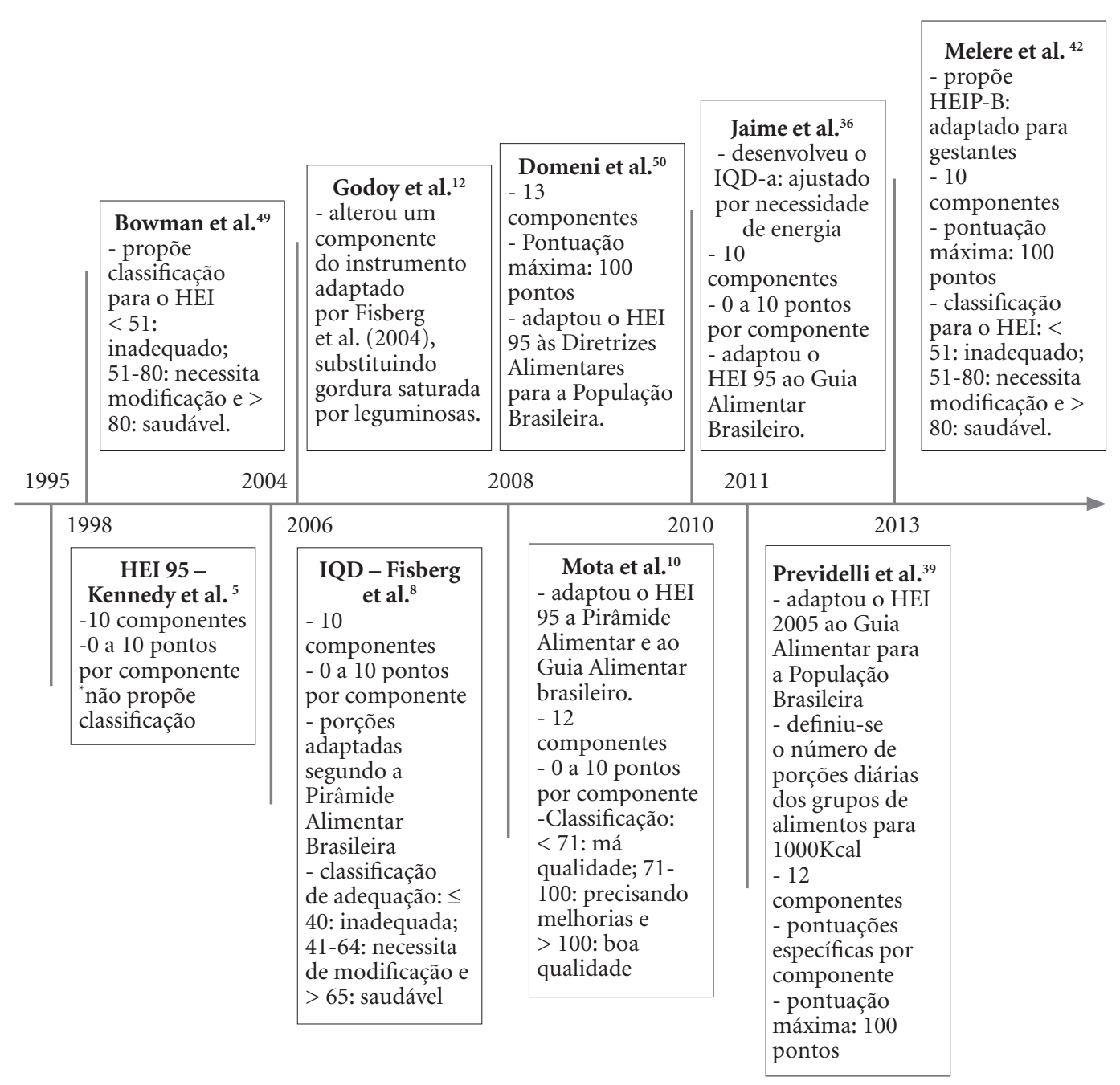

Figura 2. Histórico do Índice de Alimentação Saudável desde a sua formulação.

até 120 pontos, classificando-se em dietas de boa qualidade (superior a 100 pontos), precisando de melhorias (71-100 pontos) e má qualidade (inferior a 71 pontos). Vale ressaltar que Godoy et al. ${ }^{12}$ ao adaptar o IAS para a população de adolescentes, já havia incluído pela primeira vez o componente leguminosas, substituindo-o por gordura saturada.

Em relação a utilização da pontuação do IAS, tem sido discutido que a classificação de dietas de acordo com a pontuação total obtida não seria recomendada, já que a avaliação final não reflete necessariamente a realidade de cada componen$\mathrm{te}^{30}$. Entretanto, as pontuações podem possibilitar a distinção entre dietas de alta e baixa pon- tuação e, como sugerido por Guenther et al. ${ }^{30}$, podem possibilitar comparações entre o risco de doenças e a dieta. Caso o índice seja classificado em quintis, pode haver comparações dos riscos nos quintis mais altos e nos mais baixos. Dentre os artigos desta revisão apenas um utilizou a classificação em quintil ${ }^{26}$ e dois utilizaram quartil ${ }^{33,42}$.

Os estudos apresentaram diferentes classificações em muitos aspectos, tais como os elementos incluídos, os valores de corte utilizado e o método de pontuação. Assim, a contribuição dos componentes individuais do índice para o total de pontuação continua a ser uma questão complexa que necessita ser mais bem examinada ${ }^{51}$. Observa-se que, mesmo os estudos realizados mais recente- 
mente, mantiveram a classificação por pontuações para definição da qualidade da dieta.

Um aspecto a ser considerado quanto a utilização do IAS é a sua comparação com os parâmetros convencionais como as Dietary Reference Intakes (DRIs), pois uma pontuação satisfatória não necessariamente representa uma ingestão adequada de alguns nutrientes ${ }^{5,31}$. Cabe ressaltar que apenas um artigo selecionado fez associação do IAS com a adequação dos nutrientes ${ }^{47}$, necessitando de maiores discussões nessa área, a fim de compreender se elevadas pontuações podem refletir melhor adequação nutricional. Segundo Guenther et al..$^{52}$, para alguns nutrientes tais como Vitamina E e potássio, mesmo pontuações elevadas do índice podem não refletir valores adequados destes nutrientes.

O IAS, apesar de ter sido proposto originalmente há quase 20 anos, teve a sua aplicação no Brasil iniciada apenas em 2004, demonstrando ser um instrumento novo, o que pode ter contribuído para algumas limitações observadas em sua utilização no decorrer dos estudos. Um primeiro aspecto a ser mencionado relacionase a não padronização de inquéritos alimentares utilizados. Dentro do compilado de estudos desta revisão, observou-se o uso de inquéritos que usualmente avaliam tanto a dieta habitual, como recordatório habitual e QFA, como os que avaliam a dieta atual, recordatório 24 horas $^{41}$, registro alimentar e método de pesagem direta do alimento. Além da variabilidade de inquéritos, o número de dias avaliados também variou. Aliado a isso, os parâmetros de recomendações alimentares também diferiram entre as publicações. $\mathrm{O}$ estudo pioneiro da Fisberg et al. ${ }^{8}$, que adaptou o instrumento ao Brasil, utilizou as recomendações da pirâmide alimentar brasileira. Entretanto, alguns outros artigos conduziram seus estudos utilizando recomendações internacionais, como a pirâmide alimentar americana (USDA) e o Guia dietético para Americanos (2000) 11,12,15-18,32,34-36,40, o que dificulta a comparação de resultados na literatura para estudos nacionais quanto ao consumo da população.

Outro ponto importante relaciona-se ao fato de que os componentes do IAS contribuem com o mesmo peso na pontuação total, desconsiderando o impacto que cada grupo de alimento exerce sobre a saúde. Diante destes resultados, seria prudente, além da pontuação total, analisar separadamente cada componente ${ }^{51}$.

Outra consideração a ser feita diz respeito ao número de porções consumidas e a pontuação atribuída pelo índice. Esta pontuação é máxima quando há o consumo mínimo das porções recomendadas, não havendo, portanto, qualquer tipo de avaliação negativa para um consumo excessivo dos componentes alimentares, o que também caracteriza consumo inadequado $\mathrm{o}^{53,54}$.

Ainda com relação aos componentes, observaram-se diversas modificações neste aspecto entre os estudos, como inclusão e exclusão de itens, o que interfere na comparação adequada quando da análise de sua pontuação. Entende-se que constantes adaptações são necessárias para a população local, quando se trata de consumo alimentar e, assim, primar por um padrão de instrumento que se aproxime de forma mais estreita desse verdadeiro consumo torna-se essencial para se obter conclusões mais fidedignas.

\section{Conclusão}

De acordo com o IAS, a população brasileira encontra-se na categoria de necessidade de melhoria da qualidade da dieta, com baixa adequação do consumo para frutas, verduras e legumes, bem como leite e derivados e elevado consumo de gordura, com atenção especial para gorduras saturadas.

Muitos questionamentos acerca desses instrumentos ainda permeiam sua utilização, como as verdadeiras inferências que eles podem trazer: se de fato, conseguem avaliar a qualidade da alimentação como um todo sem considerar o impacto que cada grupo alimentar exerce sobre a qualidade da dieta. Estas questões metodológicas necessitam ser avaliadas cautelosamente com repetidas aplicações em populações distintas, para que a classificação da qualidade da dieta possa ser cada vez mais fidedigna. Vale ressaltar que as diferentes metodologias de avaliação do consumo alimentar para um mesmo instrumento dificultam as comparações entre os diferentes estudos.

\section{Colaboradores}

PRS Moreira, NP Rocha e LC Milagres participaram igualmente de todas as etapas da elaboração do artigo e JF Novaes, orientadora do estudo, foi a responsável pela revisão e aprovação do artigo final para submissão. 


\section{Referências}

1. Volp ACP, Alfenas RCG, Costa NMB, Minim VPR, Stringueta PC, Bressan J. Índices dietéticos para avaliação da qualidade de dietas. Rev. Nutr. Campinas 2010; 23(2):281-295.

2. Dam RM. New approaches to the study of dietary patterns. Br J Nutr 2005; 93(5):573-574.

3. Cervato AM, Vieira VL. Índices dietéticos na avaliação da qualidade global da dieta. Rev. Nutr. 2003; 16(3):347-355.

4. Kourlaba G, Kondaki K, Grammatikaki E, Roma-Giannikou E, Manios Y. Diet quality of preschool children and maternal perceptions/misperceptions: The GENESIS study. Public Health 2009; 123(11):738-742.

5. Kennedy ET, Ohls J, Carlson S, Fleming K. The Healthy Eating Index: Design and applications. J Am Diet Assoc 1995, 95(10):1103-1108.

6. Bowman AS, Lino M, Gerrior AS, Basiotis PP. The Healthy Eating Index: 1994-96. US Department of Agriculture, Center for Nutrition Policy and Promotion. CNPP-5. 1998,1-19. [acessado 2014 maio 16]. Disponível em: http://www.cnpp.usda.gov/sites/default/files/ healthy_eating_index/HEI94-96report.pdf

7. Philippi ST, Latterza AR, Cruz ATR, Ribeiro LC. Pirâmide alimentar adaptada: guia para escolha dos alimentos. Rev Nutr 1999; 12(1):65-80.

8. Fisberg RM, Slater B, Barros RR, de Lima FD, Cesar CLG, Carandina L, Barros MBA, Goldbaum M. Índice de Qualidade da Dieta: avaliação da adaptação e aplicabilidade. Rev. Nutr. 2004; 17(3):301-308.

9. Pattersson RE, Haines OS, Popkin BM. Diet quality index: capturing a multidimensional behavior. J Am Diet Assoc. 1994; 94(1):57-64.

10. Mota JF, Rinaldi AEM, Pereira AF, Maesta N, Scarpin MM, Burini RC. Adaptação do índice de alimentação saudável ao guia alimentar da população brasileira. Rev. Nutr. 2008; 21(5):545-552.

11. Loureiro AS, Da Silva RMVG, Rodrigues PRM, Pereira RA, Wendpap LL, Ferreira MG. Qualidade da dieta de uma amostra de adultos de Cuiabá (MT): associação com fatores sociodemográficos. Rev. Nutr. 2013; 26(4):431-441.

12. Godoy FC, Andrade SC, Morimoto JM, Carandina L, Goldbaum M, Barros MBA, César CLG, Fisberg RM. Índice de qualidade da dieta de adolescentes residentes no distrito do Butantã, município de São Paulo, Brasil. Rev. Nutr. Campinas. 2006; 19(6):663-671.

13. Da Costa D, Reis BZ, Vieira DAS, Costa JO, Teixeira PDS, Raposo OFF, De Lima FEL, Mendes-Netto RS. Índice de Qualidade da Dieta de mulheres usuárias de um programa de atividade física regular "Academia da Cidade", Aracaju, SE. Rev. Nutr. 2012; 25(6):731-741.

14. Malta MB, Papini SJ, Corrente JE. Avaliação da alimentação de idosos de município paulista - aplicação do Índice de Alimentação Saudável. Cien Saude Colet 2013; 18(2):377-384.

15. Silva FK, Prata A, Cunha DF. Frequency of metabolic syndrome and the food intake patterns in adults living in a rural area of Brazil. Revista da Sociedade Brasileira de Medicina Tropical 2011; 44(4):425-429.
16. Nespeca M, Cyrillo DC. Avaliação da qualidade da dieta por meio do índice de alimentação saudável de funcionários de uma universidade pública. Nutrire: rev. Soc. Bras. Alim. Nutr. 2010; 35(2):81-90.

17. Santos CRB, Gouveia LAV, Portella ES, Avila SS, Soares EA, Lanzillotti HS. Índice de Alimentação Saudável: avaliação do consumo alimentar de diabéticos tipo 2. Nutrire: rev. Soc. Bras. Alim. Nutr. 2009; 34(1):115-129.

18. Gomes ALC, Campino ACC, Cyrillo DC. Índice de alimentação saudável entre mulheres de diferentes estratos sociais: o caso da Vila Formosa*. Nutrire: rev. Soc. Bras. Alim. Nutr. 2008; 33(2):87-97.

19. Morimoto JM, Latorre MRDO, César CLG, Carandina L, Barros MBA, Goldbaum M, Fisberg RM. Factors associated with dietary quality among adults in Greater Metropolitan São Paulo, Brazil, 2002. Cad Saude Publica 2008; 24(1):169-178.

20. Carvalho AM, César CLG, Fisberg RM, Marchioni DML. Excessive meat consumption in Brazil: diet quality and environmental Impacts. Public Health Nutr 2013; 16(10):1893-1899.

21. Rauber F, Louzada MLC, Feldens CA, Vitolo MR. Maternal and family characteristics associated with the Healthy Eating Index among low socioeconomic status Brazilian children. J Hum Nutr Diet 2013; 26(4):369-379.

22. Rauber F, Hoffman DJ, Vitolo MR. Diet quality from pre-school to school age in Brazilian children: a 4-year follow-up in a randomised control study. $\mathrm{Br} J$ Nutr 2014; 111(3):499-505.

23. De Lima FEL, Fisberg RM, Uchimura KY, Picheth T. Programa Bolsa-Família: qualidade da dieta de população adulta do município de Curitiba, PR. Rev. bras. epidemiol. 2013; 16(1):58-67.

24. Wendpap LL, Ferreira MG, Rodrigues PRM, Pereira RA, Loureiro AS, Gonçalves-Silva RMV. Qualidade da dieta de adolescentes e fatores associados. Cad Saude Publica 2014; 30(1):97-106.

25. Tardivo AP, Nahas-Neto J, Nahas EAP, Maesta N, Rodrigues MAH, Orsatti FL. Associations between healthy eating patterns and indicators of metabolic risk in postmenopausal women. Nutr J 2010; 9(64):2-9.

26. Pimentel GD, Moreto F, Corrente JE, Port Ero-Mclellan KC, Burini RC. Associação do padrão de ingestão lípidica com a qualidade da dieta, resistência insulínica e homocisteinemia em adultos. Acta Med Port 2011; 24(5):719-726.

27. Domene SMA, Jackix EA, Raposo HF. Adaptação das diretrizes alimentares para a população brasileira e o estabelecimento do índice de alimentação saudável para pré-escolares de 2 a 6 anos. Nutrire: rev. Soc. Bras. Alim. Nutr. 2006; 31(2):75-90.

28. Portero-McLellan KCP, Pimentel GD, Corrente JE, Burini RC. Association of fat intake and socioeconomic status on anthropometric measurements of adults. $\mathrm{Cad}$ Saúde Colet 2010; 18(2):266-274. 
29. Fisberg RM, Morimoto JM, Slater B, Barros MBA, Carandina L, Goldbaum M, Latorre MRDO, César CLG. Dietary Quality and Associated Factors among Adults Living in the State of São Paulo, Brazil. J Am Diet Assoc 2006; 106(12):2067-2072.

30. Guenther PM, Reedy J, Krebs-Smith SM, Reeve BB. Evaluation of the Healthy Eating Index-2005. J Am Diet Assoc 2008; 108(11):1854-1864.

31. Guenther PM, Casavale KO, Reedy J, Kirkpatrick SI, Hiza HAB, Kuczynski KJ, Kahle LL, Krebs-Smith SM. Update of the Healthy Eating Index: HEI-2010. J Acad Nutr Diet 2013; 113(4):569-580.

32. Gomes ALC, Cyrillo DC. Utilização da rotulagem de alimentos embalados e a qualidade da alimentação de mulheres de uma região da cidade de São Paulo. Nutrire: rev. Soc. Bras. Alim. Nutr. 2006; 31(1):33-42.

33. Assumpção D, Barros MBA, Fisberg RM, Carandina L, Goldbaum M, Cesar GLG. Qualidade da dieta de adolescentes: estudo de base populacional em Campinas, SP. Rev Bras Epidemiol 2012; 15(3):605-616.

34. Barbosa RMS, Carvalho CGN, Franco VC; Salles-Costa R, Soares EA. Avaliação do consumo alimentar de crianças pertencentes a uma creche filantrópica na Ilha de Paquetá, Rio de Janeiro, Brasil. Rev. Bras. Saúde Mater. Infant. 2006; 6(1):127-134.

35. Vitolo MR, Rauber F, Campagnolo PDB, Feldens CA, Hoffman DJ. Maternal dietary counseling in the first year of life is associated with a higher healthy eating index. J Nutr 2010; 140(11):2002-2007.

36. Jaime PC, Bandoni DH, Duran ACFL, Fisberg RM. Diet quality index adjusted for energy requirements in adults. Cad Saude Publica 2010; 26(11):2121-2128.

37. Felippe F, Balestrin L, Silva FM, Schneider AP. Qualidade da dieta de indivíduos expostos e não expostos a um Programa de Reeducação Alimentar. Rev. Nutr. 2011; 24(6):833-844.

38. Oliveira EP, Camargo KF, Castanho GKF, Nicola M, Portero-McLellan KC, Burini RC. A variedade da dieta é fator protetor para a pressão arterial sistólica elevada. Cardiol 2012; 98(4):338-343.

39. Previdelli NA, Andrade SC, Ferreira SRG, Fisberg RM, Marchioni DM. Índice de qualidade da dieta revisado para a população brasileira. Rev Saude Publica 2011; 45(4):794-798.

40. Louzada MLC, Durgante PC, Marchi RJ, Hugo FN, Hilgert JB, Padilha DMP, Antunes MT. Healthy eating index in southern brazilian older adults and its association with socioeconomic, behavioral And health characteristics. J Nutr Health Aging 2012; 16(1):3-7.

41. Melendez-Araújo MS, Arruda SLM, Kelly EO, Carvalho KMB. Preoperative Nutritional Interventions in Morbid Obesity: Impact on Body Weight, Energy Intake, and Eating Quality. Obes Surg 2012; 22(12):1848-1854.

42. Melere C, Hoffmann JF, Nunes MAA, Drehmer M, Buss C, Ozcariz SGI, Soares RM, Manzolli PP, Duncan BB, Camey SA. Índice de alimentação saudável para gestantes: adaptação para uso em gestantes brasileiras. Rev Saude Publica 2013; 47(1):20-28.
43. Tavares MP, Devincenzi MU, Sachs A, Abrão ACFV. Estado Nutricional e qualidade da dieta de nutrizes em amamentação exclusiva. Acta Paul Enferm 2013; 26(3):294-298.

44. Cervato AM, Vieira VL. Índice dietéticos na avaliação da qualidade global da dieta. Rev. Nutr. 2003; 16(3): 347-355.

45. Brasil. Ministério da Saúde (MS). Secretaria de Vigilância em Saúde. VIGITEL Brasil 2013: vigilância de fatores de risco e proteção para doenças crônicas por inquérito telefônico. Brasília: MS; 2013.

46. Wanderley EM, Ferreira VA. Obesidade: uma perspectiva plural. Cien Saude Colet 2010; 15(1):185-194.

47. Levy RB, Castro IRR, Cardoso LO, Tavares LF, Sardinha LMV, Gomes FS, Costa AWN. Consumo e comportamento alimentar entre adolescentes brasileiros: Pesquisa Nacional de Saúde do Escolar (PeNSE), 2009. Cien Saude Colet 2010; 15(2):3085-3097.

48. Brasil. Instituto Brasileiro se Geografia e Estatística (IBGE). Pesquisa de orçamentos familiares 2008-2009, 2011 [acessado 2014 maio 16]. Disponível em: http:// www.ibge.gov.br/home/estatistica/populacao/condicaodevida/pof/2008_2009_analise_consumo/pofanalise_2008_2009.pdf

49. Bowman SA, Lino M, Gerrior SA, Basiotis PP. The Healthy Eatins Index: 1994-96. Washington: U.S. Departament of Agrilculture; 1998.

50. Domene S, Jackix EDA, Raposo HF. Adaptação das diretrizes alimentares para a população brasileira e o estabelecimento do índice de alimentação saudável para pré-escolares de 2 a 6 anos. Nutrire 2006; 31(2):75-90.

51. Waijers PMCM, Feskens EJM, Ocké MC. A critical review of predefined diet quality scores. Br J Nutr 2007; 97(2):219-231.

52. Guenther PM, Reedy J, Krebs-Smith SM. Development of the Healthy Eating Index - 2005. J Am Diet Assoc 2008; 108(11):1896-1901.

53. Institute of Medicine. Weight gain during pregnancy: reexamining the guidelines. Washington: The National Academies Press; 2009.

54. Olafsdottir AS, Skuladottir GV, Thorsdottir I, Hauksson A, Steingrimsdottir L. Maternal diet in early and late pregnancy in relation to weight gain. Int J Obes (Lond) 2006; 30(3):492-499.

Artigo apresentado em 26/09/2014

Aprovado em 28/01/2015

Versão final apresentada em 30/01/2015 
